\title{
Understanding the Creation of Abstract Concepts beyond the Intangible and Tangible Materials of Land Art
}

\author{
Jinvo Nam \\ Assistant Professor, Department of Landscape Architecture, Mokpo National University, Muan , Republic of Korea
}

\section{ABSTRACT}

Background and objective: Understanding abstract art as an art form requires depth of thought. Moreover, understanding land art as abstract art is challenging, given its focus on the minimalism and abstract concepts. Much focus, research, and work were actively conducted in the 1970s, as it represented an abstract expression of minimalism. The characteristics of minimalism connote abstract meanings in the use of materials. Nevertheless, the original research of works or artists has often been mentioned, but few studies have analyzed the abstract language of land art materials. The aim of this study is to thus determine the abstract meanings of materials in land art from the 1970s to the 2010s.

Methods: Art-based research was employed to address the aim. This study classified the land art materials into intangible and tangible materials, where intangible materials focused on lines, circles, and labyrinths, and tangible materials focused on the earth, stones, wood, and snow.

Results: Intangible and tangible materials of land art conveyed various abstract meanings. Intangible materials were reflective of connection and symbiosis with nature, delivering abstract languages of 'take-nothing,' 'reflection' and 'opportunity.' Tangible materials reflected the abstract concepts of 'intervention,' 'resistance,' 'unliving,' and 'change,' and conveyed caveats. In other words, taken together, intangible and tangible materials were presented in symbiosis-and with caveats-and delivered messages for the present and the future. Interestingly, intangible materials inherently reflect symbiosis and communicate caveats in works based on a non-contextualized present and future.

Conclusion: Interpretation of the abstract languages derived from intangible and tangible materials could imply a symbiosis between humans and nature, while conveying the message that caveats, to humans, are still ongoing. This relationship plays a significant role in an artist's selection of a medium, which is reflective of abstract beliefs reflected in contemporary, nature-based works created on Earth.

Keywords: art materials, abstract art, symbiosis, minimalism, decontextualized symbiosis

\section{Introduction}

The ability to understand and interpret art requires deep thinking. It is a great challenge to comprehend the 'what, why, and how' of a work of art. Moreover, certain forms of art, such as abstract art, require even more extensive thinking. One specific instance is land art, which is a very well-known type of abstract art that aims to compel its viewers into deep rumination. Land artworks have expressed various abstract meanings, including minimalism, beauty, views against excessive industrialism, and others. Many land art works have been explored in an attempt to derive specific abstract meanings; these meanings have already been mentioned in many earlier studies. However, little research has sought to understand intangible and tangible materials as media with abstract meanings. Intangible and tangible materials can be distinguished in terms of features such as sight, feel, and touch, as well as physical existence (Westin, 2016). This remains a point of contention for certain materials, such as a line that a person can see, but that they cannot feel or touch.

Received: November 21, 2021, Revised: December 7, 2021, Accepted: December 10, 2021

First author: Jinvo Nam, jinvo.nam@gmail.com, (1) https://orcid.org/0000-0002-3094-1018

*Corresponding author: Jinvo Nam, jinvo.nam@gmail.com, (1) https://orcid.org/0000-0002-3094-1018 
Therefore, the term 'line' is considered to have an intangible meaning. Intangible materials such as a line, circle, and labyrinth have often been incorporated into land artworks. However, we do not know their intended intangible meanings. Tangible materials such as earth, stone, wood, and snow have often been used in land artworks as well; however, we also do not know which aspects of land art were expected to be depicted using intangible and tangible materials. This point requires further study. The aim of this study is thus to grasp the intangible meanings of land art in terms of the materials used and the messages they intend to convey about the future. To this end, this study explores land artworks employing various materials of interest.

\section{Research Methods}

This study employed art-based research, which is an approach to formal qualitative inquiry that intends to articulate and understand the subjectivity of artists' works (Savin-Baden and Wimpenny, 2014). All land artworks, the previous literature on the subject, and the land artworks selected in this study were used as materials. This study analyzed two different materials to determine how they were used as forms of artistic expression and elicited creative interpretation.

\section{Results and Discussion}

\section{Intangible materials: line, circle, and labyrinth}

The distinguishing features of land art are the languages spoken by the materials used, which are characterized by moderation and the use of geometry. The line, circle, and labyrinth are the most frequently used intangible materials, and hold symbolic meaning.

\section{Taking nothing: The line}

The line is used as a language element in all types of art, and has held a wide range of connotations throughout history (Weilacher, 1999). There is no doubt that the form or design material of 'the line' is one of the most fundamental one-dimensional signs. To land artists, the line is essential to communicating a specific meaning, such as in minimalism. In some examples of land artworks, the line is often shown in different concepts. In land art, the meaning of a line is extremely subjective and does not enforce morphological effects. In other words, it is concerned with symbolic and abstract meanings. Its quintessential meanings are tied to symbolism in abstractness, rather than reflective of the objective form of the line. For instance, see Richard Long's "Walking a Line in Peru” (1972; Fig. 1A), and "A Line in the Himalayas" (1975; Fig. 1B), wherein the lines are barely visible from up close.

In contrast, from a distant view, the lines form many-sided objects that make the works visible. In other words, the meaning of the line was extremely subjective. The present work digs into such subjective meanings. These works might be delivering the message of 'taking nothing', implying that the intention was to seek beauty and metaphor while walking forward and backward. Similarly, the goal was to embed nature within the world, thus delivering messages that connect nature through minimalism, which is expressed in the works as 'taking nothing.' The intangible
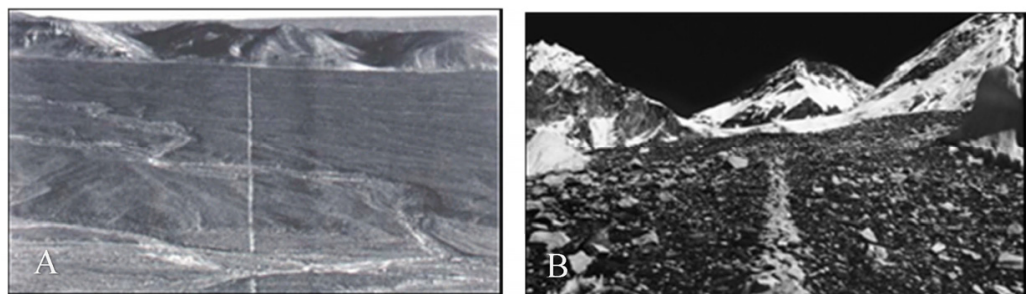

Fig. 1. Richard Long's “Walking a Line in Peru” (1972; A) and “A Line in the Himalayas” (1975; B).

Source: http://rolu.terapad.com/index.cfm?fa=contentNews.newsDetails\&newsID=113318\&from=li and http://www. richardlong. org/ Sculptures/2011sculpupgrades/himalaya.html 

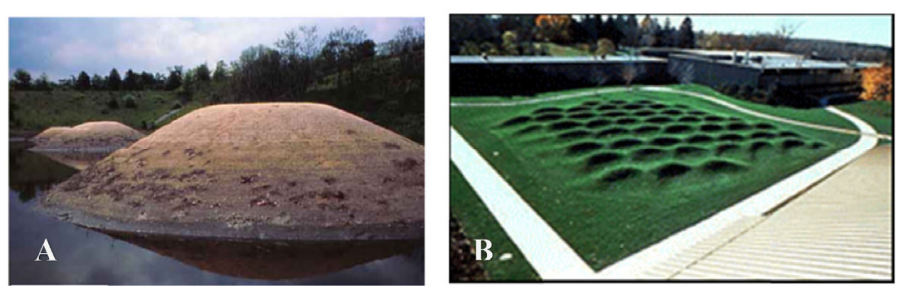

Fig. 2. Judy Varga's “Geometry of Echoes Converge” (1980; A) and Maya Lin's “The Wave Field” (1995; B). Source: http://www.vargart.net/pages/regularpages/rituals-01.htm and http://www.pbs.org/art21/artists/lin/card2.html
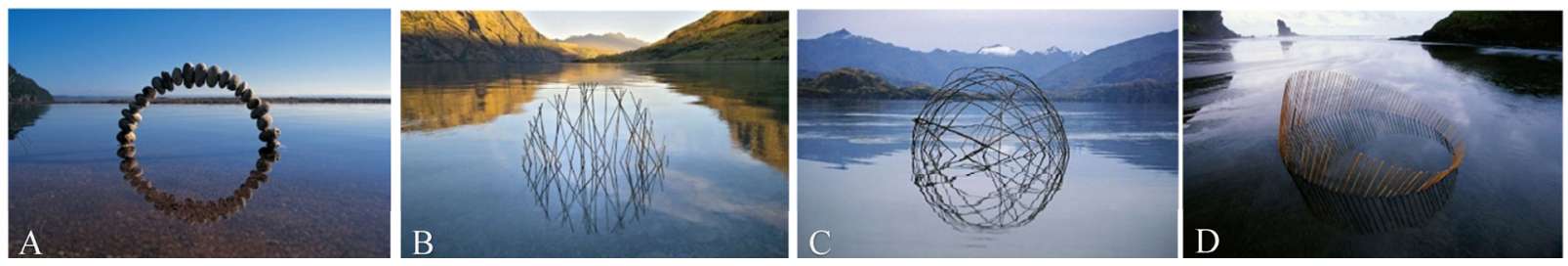

Fig. 3. Stone Circle, Sunrise Circle, Kanuka Sphere, and Rising Circle.

Source: https://mymodernmet.com/martin-hill-environemental-sculpture-art/

meaning of the line is thus a connection to nature in pursuit of minimalism, and against the excessive changes taking place during that time.

\section{Reflection: The circle}

"Whether the symbol of the circle appears in primitive sun worship or in modern religion, in myths or dreams, in the mandalas drawn by Tibetan monks, in the ground-plans of cities, or in the spherical concepts of early astronomers, it always points to the single most vital aspect of life-its ultimate wholeness" (Jung, 1964). The circle motif-one of the primeval symbols of eternity, cycles, time, rebirth, and so on-is employed throughout much land art (Malpas, 2004). Given its primitive motif, the size of a circle in land art has a general tendency to be very big, but not detailed or delicate. In the context of land art, the circle symbolizes a specific concept that is derived from various motifs in primitive mythologies or religions. The motif fundamentally connotes a common denominator that stands for harmony with nature, as well as a return to nature. This is exhibited in some land artworks, such as Judy Varga's "Geometry of Echoes Converge" (1980; Fig. 2A), Maya Lin's “The Wave Field” (1995; Fig. 2B), and other works.

However, recent land artworks have used circles to symbolize a medium or a conduit. This can be seen in contexts wherein circles were used to connect people to nature through reflection. For instance, in the works presented in Fig. 3A, the circles are used to represent interconnected threads within nature, and are intended to reflect nature.

Due to their lightness, pumice stones were used to create a hole that was designed to thread to an area in nature that was further away, while reflecting a half circle in the shallow water (thus presenting as a stone circle). The circle in Fig. 3B was pushed into nature (water, specifically) at sunrise to catch the light and calm the water for reflection. The pliable sticks in Fig. 3C show both the flooding of nature given the high lake levels, as well as beings reflected on the surface of the lake. A rising circle (Fig. 3D) is reminiscent of cyclical processes in human industrial systems that mirror nature. Rethinking the land artworks above arouses reflection about the changes currently occurring in nature, as well as humanity's connection to nature.

Opportunity: The labyrinth

The 'labyrinth' material is often favored by land artists, and it appears in many land artworks. The labyrinth is a very satisfying motif or design: it is self-contained, like other geometric patterns, and it can take on almost any perimeter shape, from circles and squares to 'organic' shapes (Malpas, 2004).

In modern times, labyrinths have become public areas and amenities and serve as features that visitors can enjoy. 

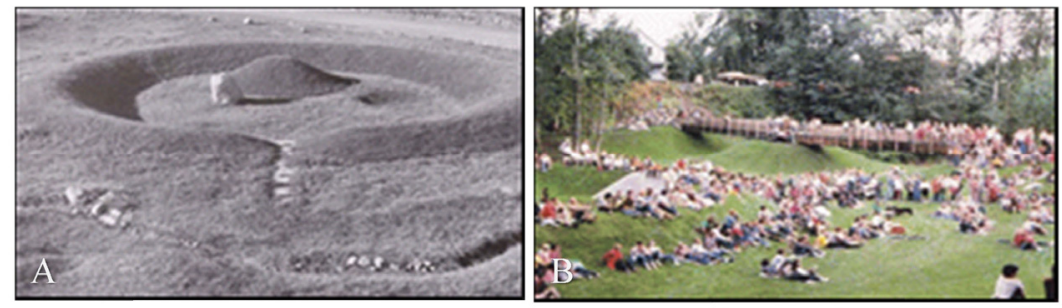

Fig. 4. Herbert Bayer's “Earth Mound” (1995; A) and "Mill Creek Canyon Earthworks” (1979-82; B). Source: Beardsley, J. (2006) Earthworks and Beyond. p. 86

The use of labyrinths by land artists can be seen as part of the resurgent interest in mazes that occurred in the $1980 \mathrm{~s}$ (aligned, as always, with green/ecological/occult/new-age trends) in which labyrinths were sometimes placed next to children's playgrounds, thus promoting a sense of play, rather than conveying any ritualistic meaning (Malpas, 2004). The 'labyrinth' may be a social design form used to commune with the public. In some land artworks, such as Herbert Bayer's "Mill Creek Canyon Earthworks" (1979-82; Fig. 4A), use of a labyrinth form in the grass ground is sufficient for appealing to a contemporary audience (Fig. 4B).

The intangible meaning conveyed by a labyrinth is the connection between nature and people. Having a single path is the fundamental element of a labyrinth, but it gives alternatives or options to provide uncertainty. This evokes a sense of a complicated world filled with uncertainty. However, a complicated network implies an inevitable connection between nature and people.

\section{Tangible materials: earth, stone, wood, and snow}

\section{Intervention: Earth}

All works may be created using earth, and land art is no exception. The use of land artworks made from earth is, ironically, not a positive statement; it means that land art is, in all aspects, based on the earth as a material, which involves simultaneously pursuing demolition and a return to the fundamentally intact condition of earth. Earth, this special material in land art, is bound up with post-modernism, particularly in our paradigm. It has negative connotations, as it is associated with dirt, filth, and abuse. It is a fundamental driver that contains substance and arouses factors immanent in social evolution. In other words, the earth is a canvas on which to show substantial matters. This represents a relocation of the canvas from inside to outside. For example, this can be seen in Nam's 2021 study, which showed that the substance of land art moved from in (general sculpture) to out (land). These unobtrusive markings are used to formulate many types of spectacular interventions using the earth as a large canvas. Therefore, land art aims to present the negative aspects of earth, and aims to rescue the earth from devastation. The choice to use earth sublimates the devastated land in land art.

\section{Resistance: Stone}

Stone might be one of the most important materials, and has been used by man for thousands of years. It is also a material that is readily available and widely used in works by land artists. Importantly, numerous land artists have used unworked stone in this way, thus evoking its diverse traditional symbolism: stability, endurance, reliability, immorality, permanence, and the eternal. Moreover, every stone-and every unhewn or erratic stone in particular-tells a part of the history of the landscape through its location, the type of rock it is, and its form, thus strengthening the relationship of the work itself to the place (Weilacher, 1999). This can be seen as the reason why land artists prefer to use unworked stone. Meanwhile, stone featured in land art serves as a medium wherein each stone is used to create and convey a new meaning (Fig. 5).

Each stone is just one of the many materials used in land art. However, the gathering or grouping of stones has a powerful meaning that land artists use to present certain ideas. The use of unworked stone might hold the abstract meaning of being resistant to post-modernism, as far as 

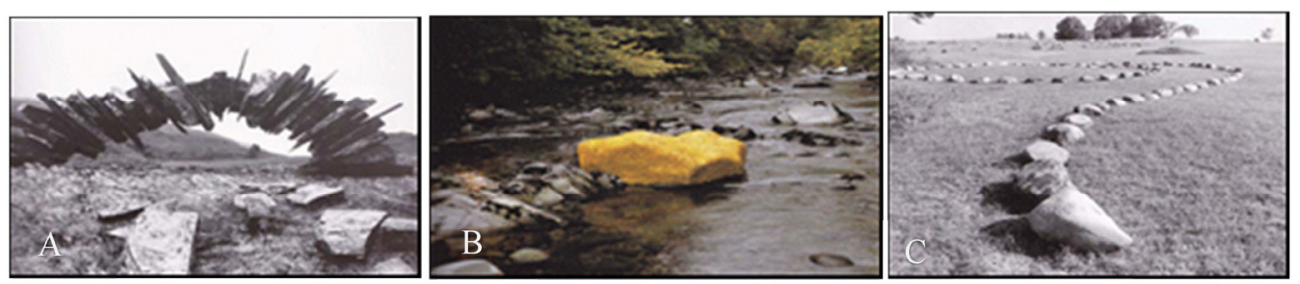

Fig. 5. Andy Goldsworthy's "Arch" (1982), stone, Blaenau Ffestiniog, Wales (A), Andy Goldsworthy's "Yellow Elm Leaves Laid over a Rock," low water, Dumfriesshire, Scotland (B), and James Pierce's "Stone Serpent" (1979), Pratt Farm (C).

Source: Beardsley, J. (2006) Earthworks and Beyond. p53, 51, 71
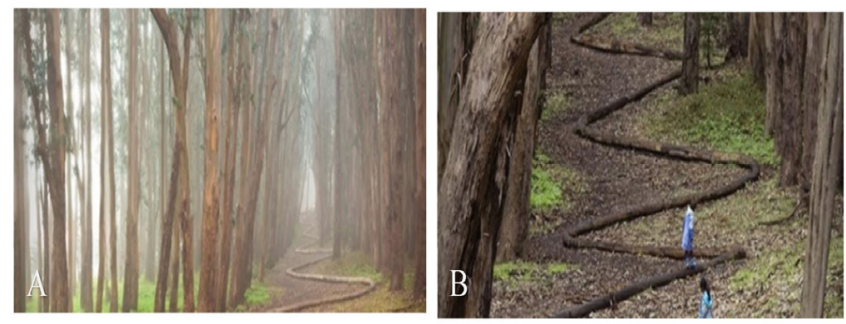

Fig. 6. Goldsworthy's 'Wood Line'.

Source: https://www.presidio.gov/places/andy-goldsworthys-wood-line

the term 'machining' has been a symbol of post-modernism that has dominated most industries through destruction. Of the various land art materials, stone is the most resistant to destruction, as it employs more natural, unworked, and coarse stones.

\section{Unliving: Wood}

Wood as a sculptural material is still used today in three essential ways: first, it is used in wood carving; second, it is used as a construction material, such as to create beams and planks; and third, it is integrated in its natural form as a tree, trunk, or branch (Tomlinson, 1983). Land art tends to use wood most frequently as a means for construction. Wood is the most dynamic living material that can adapt to nature. Living plants often develop an unpredictable momentum of their own, and therefore actively alter their forms and properties. Wood is attractive in a variety of texture, forms, and colors. Wood is also used as a supporting land art to express main themes because it is a flexible material and can express different concepts. However, the land art material of 'wood' represents a strong symbol between the living and the unliving. The use of unliving wood is generally dominated by man; man might therefore stand for the living. In Fig. 6, Goldsworthy's first Presidio piece, 'Wood Line', offers a stark contrast with the towering "Spire".

While "Spire" calls upon viewers to look up, "Wood Line" invites you to contemplate while you step or walk on the unliving woods, where the life of a tree ends.

\section{Changes: Snow}

Expressive actions in land art focus on individual and sometimes whimsical encounters with landscapes, nature, and time (Weilacher, 1999). In a part of the project titled "Time Pocket," Dennis Oppenheim-an American artist that was the first to work with snow on a grand scale-used a snowmobile to make a line in the snow (Fig. 7).

His motifs involve borders, margins, and thresholds in time, space, and concept. Using snow and ice in land art symbolises the expression and flow of time, while simultaneously recognizing the natural phenomena that we have never noticed. An example is Andy Goldworthy's "Snow and Ice" (2009), which melted only a short time later (Fig. 8).

The work disappeared quickly, and only photo, sketch, text, and other records remain. However, the meaning of the expression of this artwork is a negative response to 

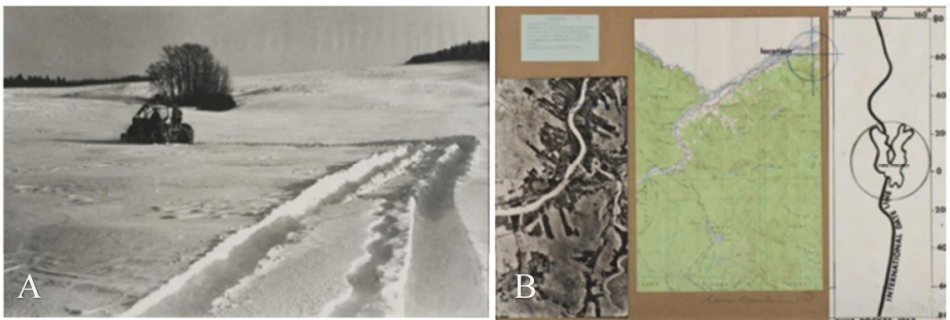

Fig. 7. Dennis Oppenheim's “Time Pocket” (A) and brain storming (B).

Source: http://www.artnet.com/artists/dennis-oppenheim/time-pocket-FJMdNEivpD_Q3rl_1T9TdA2
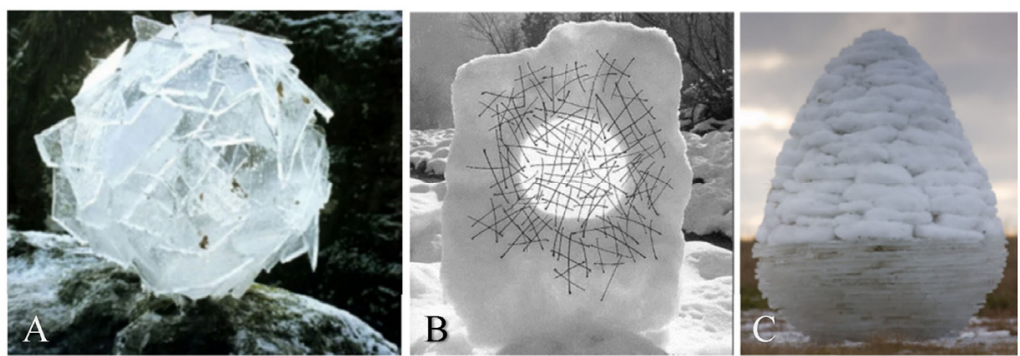

Fig. 8. Land art works in Andy Goldworthy's "Snow and Ice”.

Sources: https://aesthesiamag.wordpress.com/2017/12/31/andy-goldsworthys-ice-and-snow-ephemeral-sculptures/
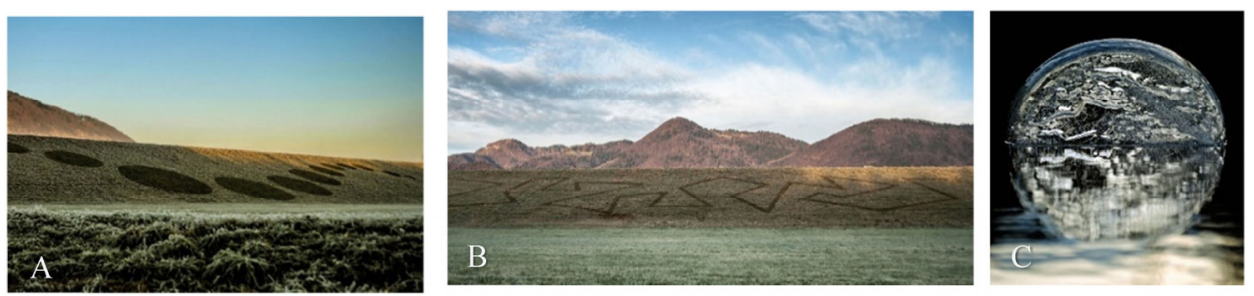

Fig. 9. Miha Brinovec's land artworks: "Pograbljeno Ivje” (A), "Risbe na Ivju” (B), and "Ledv Void, Ice" (C). Sources: https://mihabrinovec.wixsite.com/mb-art/snow--ice

the changing environment. The intentions are to impose human-made geometric symbols and ideas on the landscape. As it is capable of 'melting,' snow was used in land artworks of the 1970 s to issue a strong warning about the devastation of Earth. Unfortunately, this this is apparent all over the world. These warnings have recently found renewed use in several land artworks. As shown in Fig. 9, these land artworks may pose warnings about the art of the living by evoking the closeness of death using melting snow. This certainly has implications for the places and moments.

\section{Symbiosis and caveats}

The symbiosis between man and nature is often used to serve as a warning to man to contextualize nature, as communicated through the use of intangible and tangible materials in land artwork. Broadly speaking, the importance of symbiosis with nature has been underlined in nature-related works since at least the 1970s; in particular, the term 'symbiosis' has shown up often within land artworks. There is a concern that this notion is persisting and reflected in nature-based works. It is perhaps doubtful that man would still dominate nature under the scant rationalization that man stresses to pursue symbiosis with nature. Land art, while emphasizing the importance of minimalism against the rapid process of industrialization and the constant disappearance of nature, is evident when highlighting the term 'symbiosis' rather than 'domination.' For example, 
melting snow in land artworks has been used to show the horrors of climate change. This may be an unwanted change, but it is still ongoing. Intangible and tangible materials in land art have alluded to this decontextualized symbiosis, which is still occurring now and continuing to issue warnings for the future.

\section{Conclusion}

Abstract art requires depth of thought. Understanding land art as a form of abstract art remains a great challenge. Materials in land art can be classified into intangible and tangible materials. Intangible materials (lines, circles, and labyrinths) deliver a variety of abstract meanings. They convey the meaning of 'connection with nature,' transmitting the meanings of 'take nothing,' 'reflection' and 'opportunity.' Meanwhile, tangible materials (earth, stone, wood, and snow) in land art show strong abstract notions, expressing messages such as 'intervention,' 'resistance,' 'unliving' and 'change.' They also transfer meaningful messages for the present and the future. Intangible and tangible materials allude to decontextualized symbiosis and warnings for the future, as well as for the present, as many of the messages were delivered in the 1970s. Not only is this in line with the findings of previous studies, but land artworks can also deliver stronger warnings through nature-based works, depending on the utilization of various materials. In conclusion, interpreting the intangible and tangible materials used in land art shows that the abstract meanings of 'symbiosis between man and nature' and 'caveats to man' are still relevant.

\section{References}

Beardsley, J. 2006. Earthworks and Beyond; Contemporary Art in the Landscape. New York: Cross River Press.

Jung, C. 1964. Man and his History. Washington, USA: Turtleback Books.

Malpas, W. 2004. Land Art: A Complete to Guide. Kent, UK: Crescent Moon Publishing.

Nam, J. 2021. Critical discourse on land arts in the context of landscape architecture. J. Korea Inst. Gard. Des. 7(2):93-101. http://doi.org/10.22849/jkigd.2021.7.2.002

Savin-Baden, M. and K. Wimpenny. 2014. A Practical Guide to Arts-related Research. Rotterdam, Netherlands: Sense Publishers.

Tomlinson, P. B. 1983. Tree Architecture: New approaches help to define the elusive biological property of tree form. Am. Sci. 71(2):141-149. Retrieved from http:// www.jstor.org/stable/27851897

Weilacher, U. 1999. Between Landscape Architecture and Land Art. Basel, Berlin, Boston: Birkhäuser.

Westin, S. 2016. The Paradoxes of Planning: A PsychoAnalytical Perspective. London, UK: Routledge.

http://rolu.terapad.com/index.cfm?fa=contentNews.news Details\&newsID $=113318 \&$ from $=\mathrm{li}$

http:/www.richardlong.org/Sculptures/2011sculpupgrades/ himalaya.html

https://www.presidio.gov/places/andy-goldsworthys- wood-line http://www.artnet.com/artists/dennis-oppenheim/timepocket-FJMdNEivpD_Q3rI_1T9TdA2

https://aesthesiamag.wordpress.com/2017/12/31/andy-goldsworthys-ice-and-snow-ephemeral-sculptures/

https://mihabrinovec.wixsite.com/mb-art/snow-ice 